\title{
Novel evidence that pituitary sex hormones regulate migration, adhesion, and proliferation of embryonic stem cells and teratocarcinoma cells
}

\author{
ZACHARIAH PAYNE SELLERS $^{1 *}$, KAMILA BUJKO $^{1 *}$, GABRIELA SCHNEIDER $^{1}$, \\ MAGDALENA KUCIA $^{2}$ and MARIUSZ Z. RATAJCZAK ${ }^{1,2}$ \\ ${ }^{1}$ Stem Cell Institute at James Graham Brown Cancer Center, University of Louisville, Louisville, KY 40202, USA; \\ ${ }^{2}$ Department of Regenerative Medicine, Medical University of Warsaw, 02-091 Warsaw, Poland
}

Received July 6, 2017; Accepted November 7, 2017

DOI: 10.3892/or.2017.6108

\begin{abstract}
The pituitary sex hormones (SexHs): follicle-stimulating hormone (FSH), luteinizing hormone ( $\mathrm{LH})$, and prolactin (PRL) regulate several functions crucial for reproduction, including oogenesis, spermatogenesis, and lactation. An important source of prolactin-like hormones, known as lactogens, is the placenta, and lactogens bind to the PRL receptor (PRLR) with high affinity and thereby mimic the actions of PRL. Recently, it has been demonstrated that pituitary SexHs were involved in metastatic lung cancer, certain sarcomas, and leukemia. In the present study we aimed to investigate whether FSH, LH, and PRL were able to stimulate stem cells involved in early development. To address this issue we employed a murine embryonic stem cell line (ES-D3) as well as two teratocarcinoma cell lines, P19 (murine) and NTera2 (human). We determined that all these cells expressed SexH receptors at the mRNA and protein levels and that stimulation of these receptors induced phosphorylation of p42/44 MAPK, p38 MAPK, and AKT. Moreover, ES-D3, P19, and NTera2 cells responded with increased migration and adhesion to physiological concentrations of pituitary SexHs. In view of these findings we proposed that maternal-derived pituitary SexHs regulate the biology of stem cells involved in early development.
\end{abstract}

\section{Introduction}

It is well known that sex hormones (SexHs) regulate the growth and function of the reproductive organs and are responsible

Correspondence to: Professor Mariusz Z. Ratajczak, Stem Cell Institute at James Graham Brown Cancer Center, University of Louisville, 500 South Floyd Street, Louisville, KY 40202, USA

E-mail: mzrata01@louisville.edu

*Contributed equally

Key words: FSH, LH, PRL, embryonic stem cells, teratocarcinoma, chemotaxis for the development of secondary sex characteristics. While peptide-based sex hormones, including follicle-stimulating hormone $(\mathrm{FSH})$, luteinizing hormone $(\mathrm{LH})$, and prolactin (PRL), are secreted by the pituitary gland, steroid SexHs, such as estrogens, androgens, and progesterone, are released from the ovaries or testes. Notably, an important source of SexHs during development is the placenta $(1,2)$. In parallel, as previously postulated, maternally-derived SexHs may also affect the developing embryo $(3,4)$.

Evidence has accumulated which revealed, that as potent mitogens, SexHs play an important role in the development and progression of cancers arising from tissues that are sensitive to SexH stimulation, such as the gonads, uterus, prostate, and breast (5-8). However, it has been recently demonstrated that both pituitary- and gonad-derived SexHs also play a role in the pathogenesis of other malignancies, such as lung cancer (9), rhabdomyosarcoma (10) and leukemia (11), and direct migration and adhesion of cells derived from these malignancies.

It has been previously postulated by us and other researchers that the most primitive stem cells residing in adult tissues share several characteristics with primordial germ cells (PGCs), which are precursors of gametes and most likely precursors of stem cells in other tissues (12-14). This tempting hypothesis suggests that in postnatal tissues there are stem cells endowed with embryonic/epiblast/germline potential. In fact, in adult tissues stem cells, now known as very small embryonic-like stem cells (VSELs), have been identified to fulfill some of these criteria $(15,16)$. These small cells have been found to be involved in physiological tissue and organ rejuvenation, but it is hypothesized that in some situations they also give rise to malignancies (17).

The notion that a population of stem cells involved in early development resides in adult tissues may corroborate the 150-year-old 'embryonic rest hypothesis' of cancer development. In the middle of the XIX century, two German pathologists, Rudolf Virchow and Julius Cohnheim, proposed this intriguing hypothesis, in which cancer may develop from embryonic cell remnants that remain in the developing organs following embryogenesis $(18,19)$. This hypothesis was popular among pathologists in the 19th and 20th centuries but later was largely abandoned. In fact, the morphology of most 
primitive tumors often mimics tissues in early development, and such tumors may express markers that are characteristic of embryonic, epiblast, and/or germline cells. Recently, we demonstrated that as postulated the most primitive stem cells residing in adult tissues, VSELs express functional SexH receptors (20-25).

To pursue this idea we investigated whether SexHs play a role in regulating the biology of the murine embryonic ES-D3 cell line as well as the murine P19 teratocarcinoma cell line and the human embryonal carcinoma NTera2 cell line. The results revealed that these cells derived in early development expressed SexH receptors at the mRNA and protein levels, and stimulation of these receptors induced phosphorylation of p42/44 MAPK, p38 MAPK, and AKT. Moreover, ES-D3, $\mathrm{P} 19$, and NTera2 cells responded with increased migration and adhesion to physiological concentrations of $\mathrm{FSH}, \mathrm{LH}$, and PRL. With these results in mind we proposed that pituitary SexHs regulate the biology of stem cells involved in early development.

\section{Materials and methods}

Cell lines. All cell lines were obtained from the American Type Culture Collection (ATCC; Manassas, VA, USA). The human multipotent embryonal carcinoma cell line NTera2 was cultured in Dulbecco's modified Eagle's medium (DMEM) supplemented with $10 \%$ fetal bovine serum (FBS). The murine teratocarcinoma cell line P19 was cultured in minimum essential medium Eagle- $\alpha$ modification (MEM- $\alpha$ ) with ribonucleosides and deoxyribonucleosides, supplemented with $7.5 \%$ bovine calf serum (BCS) and 2.5\% FBS. The murine embryonic stem cell line ES-D3 was cultured in DMEM supplemented with $15 \%$ heat-inactivated FBS and $10 \mathrm{ng} / \mathrm{ml}$ leukemia inhibitory factor (LIF). All media contained $100 \mathrm{U} / \mathrm{ml}$ penicillin and $10 \mu \mathrm{g} / \mathrm{ml}$ streptomycin. All cells were cultured in a humidified atmosphere of $5 \% \mathrm{CO}_{2}$ at $37^{\circ} \mathrm{C}$. The media was changed every $48 \mathrm{~h}$, and the cells were split upon reaching confluency as previously described (26).

RT-PCR analysis. Total RNA was isolated using the RNeasy Mini kit, including treatment with DNase I (both from Qiagen Inc., Germantown, MD, USA). The purified mRNA (2,500 ng) was afterwards reverse-transcribed into cDNA using the First Strand cDNA Synthesis kit (Thermo Scientific, Waltham, MA, USA) according to the manufacturer's instructions and using a mixture of oligo(dT) and random hexamers. Amplification of the synthesized cDNA fragments was carried out using AmpliTaq Gold ${ }^{\circledast}$ Polymerase (Applied Biosystems, Foster City, CA, USA) and sequence-specific primers (Table I) with 1 cycle of $8 \mathrm{~min}$ at $95^{\circ} \mathrm{C} ; 2$ cycles of $2 \mathrm{~min}$ at $95^{\circ} \mathrm{C}, 1 \mathrm{~min}$ at $60^{\circ} \mathrm{C}$, and $1 \mathrm{~min}$ at $72^{\circ} \mathrm{C} ; 40$ cycles of $30 \mathrm{sec}$ at $95^{\circ} \mathrm{C}, 1 \mathrm{~min}$ at $60^{\circ} \mathrm{C}, 1 \mathrm{~min}$ at $72^{\circ} \mathrm{C}$; and 1 cycle of $10 \mathrm{~min}$ at $72^{\circ} \mathrm{C}$.

Flow cytometric analysis. Cells were detached using non-enzymatic reagent CellStripper ${ }^{\circledR}$ (Corning Costar, Lowell, MA, USA), followed by a 3-h incubation in appropriate medium with $0.5 \%$ BSA. Then, the cells were washed with phosphate-buffered saline (PBS), fixed by a 20 -min incubation at RT in $3.7 \%$ paraformaldehyde, washed again, and incubated for $30 \mathrm{~min}$ in $2.5 \% \mathrm{BSA}$ in PBS. The cells were then stained with primary rabbit polyclonal anti-FSHR antibody (1:50, cat. no. sc-13935) or rabbit polyclonal anti-LHR antibody (1:50, cat. no. sc-25828) (both from Santa Cruz Biotechnology Inc., Santa Cruz, CA, USA) for $1.5 \mathrm{~h}$ at $37^{\circ} \mathrm{C}$. The cells were then washed and incubated with FITC-conjugated secondary anti-rabbit antibody (1:100, cat. no. 12154D; BD Biosciences, San Jose, CA, USA). Subsequently, the cells were analyzed using an LSR cell cytometer (BD Biosciences). Analysis of the data was performed using FlowJo 7.2.5 software (FlowJo, Ashland, OR, USA), and the cells incubated with secondary antibody only were used as controls (1:100, cat. no. 12154D; BD Biosciences).

Phosphorylation of intracellular pathway proteins. The P19 and ES-D3 cell lines were incubated overnight and the NTera2 cell line for $9 \mathrm{~h}$ in appropriate medium containing $0.5 \%$ BSA to render the cells quiescent. The cells were then stimulated with pituitary hormones (all from ProSpec-Tany TechnoGene Ltd., Ness-Ziona, Israel): FSH $(10 \mathrm{U} / \mathrm{ml}), \mathrm{LH}(10 \mathrm{U} / \mathrm{ml})$, and PRL $(0.5 \mu \mathrm{g} / \mathrm{ml})$ at $37^{\circ} \mathrm{C}$ for $5 \mathrm{~min}$, then lysed for $20 \mathrm{~min}$ on ice in RIPA lysis buffer (Santa Cruz Biotechnology Inc.) containing protease and phosphatase inhibitors (Sigma-Aldrich, St. Louis, MO, USA). The extracted proteins were separated on a $12 \%$ sodium dodecyl sulfate-polyacrylamide gel electrophoresis (SDS-PAGE) gel and transferred to a polyvinylidene difluoride (PVDF) membrane. Phosphorylation of the serine/threonine kinase AKT (phospho-AKT473, cat. no. 9271, dilution 1:1,000) and p44/42 mitogen-activated kinase (phospho-p44/42 MAPK, cat. no. 9101, dilution 1:2,000) was detected by rabbit antibodies with HRP-conjugated goat anti-rabbit secondary antibodies (cat. no. 7074S, dilution 1:5,000). Phosphorylation of the p38 mitogen-activated kinase (phospho-p38 MAPK, cat. no. 9216, dilution 1:1,000) was detected by mouse antibody with HRP-conjugated goat anti-mouse secondary antibody (cat. no. 7076, dilution 1:5,000). Equal loading in the lanes was evaluated by stripping the blots and reprobing with anti-AKT (cat. no. 9272, dilution 1:1,000) and anti-p38 MAPK (cat. no. 9212, dilution 1:1,000) rabbit antibodies followed by incubation with HRP-conjugated goat anti-rabbit secondary antibody (cat. no. 7074S, dilution 1:5,000) or with anti-p42/44 MAPK mouse monoclonal antibody followed by incubation with HRP-conjugated goat anti-mouse secondary antibody (cat. no. 7076, dilution 1:5,000). All antibodies were purchased from Cell Signaling (Danvers, MA, USA). The membranes were developed with enhanced chemiluminescence (ECL) reagent (Amersham Life Sciences, Arlington Heights, IL, USA) and subsequently exposed to film (Hyperfilm; Amersham Life Sciences, Arlington Heights, IL, USA).

Chemotaxis. Chemotaxis assays were performed in a modified Boyden's chamber with $8-\mu \mathrm{m}$ polycarbonate membrane inserts (Costar Transwell; Corning Costar) as previously described (24). Cell suspensions were quiescent for $0.5-2 \mathrm{~h}$ in medium with $0.2 \%$ BSA. Prior to experiments the inserts were covered with $1 \%$ gelatin in PBS for $1 \mathrm{~h}$ at $37^{\circ} \mathrm{C}$. Immediately after gelatin removal, the cells were seeded into the upper chamber of an insert at a density of $8-12 \times 10^{4}$ cells $/ 100 \mu 1$. The lower chamber was filled with pre-warmed DMEM (for NTera2 and ES-D3) or MEM- $\alpha$ (for P19) containing test reagents. The medium supplemented with vehicle was used 
Table I. List of primers used in this study.

\begin{tabular}{|c|c|c|}
\hline & \multicolumn{2}{|c|}{ Murine primers } \\
\hline & Forward & Reverse \\
\hline FSHR & TCAACGGAACCCAGCTAGATG & GTCTAAAACGACTGGCCCAGAG \\
\hline LHR & ATCTGTAACACAGGCATCCGG & CGTTCCCTGGTATGGTGGTTAT \\
\hline PRLR & TGCTTGCTGGGAAGTACGG & GGTGACGGAGATAGTTGGGG \\
\hline $\mathrm{ER} \alpha$ & GCCAAGGAGACTCGCTACTGTG & TGTCAATGGTGCATTGGTTTGT \\
\hline $\mathrm{ER} \beta$ & TACCCCTTGGCTACCGCAA & GCATCAGGAGGTTGGCCAG \\
\hline ProgR & TCGACAGCTTGCATGATCTTG & CCAGTGTCCGGGATTGGAT \\
\hline AR & GACTGCATGTACGCGTCGC & GGCGTAACCTCCCTTGAAAGAG \\
\hline \multirow[t]{3}{*}{ BMG } & CATACGCCTGCAGAGTTAAGC & GATCACATGTCTCGATCCCAGTAG \\
\hline & \multicolumn{2}{|c|}{ Human primers } \\
\hline & Forward & Reverse \\
\hline FSHR & GCTTCTGAGATCTGTGGAGGTT & GGACAAACCTCAGTTCAATGGC \\
\hline LHR & CCGGTCTCACTCGACTATCAC & TGAGGAGGTTGTCAAAGGCA \\
\hline PRLR & CTGGGCTTTCTGCCTTACTCA & TTCTTTAGTTTTGCCAGGGAGCA \\
\hline $\mathrm{ER} \alpha$ & AGGTGCCCTACTACCTGGAG & CGGTCTTTTCGTATCCCACCT \\
\hline $\mathrm{ER} \beta$ & TTTTTGGACACCCACTCCCC & CACCTGTTGAGGAAAGCGAG \\
\hline ProgR & CGGACACCTTGCCTGAAGTT & CGGACACCTTGCCTGAAGTT \\
\hline AR & CGACTTCACCGCACCTGATG & СTTCTGTTTCCCTTCAGCGG \\
\hline$\beta$-actin & GGATGCAGAAGGAGATCACTG & GGATGCAGAAGGAGATCACTG \\
\hline
\end{tabular}

FSHR, follicle-stimulating hormone receptor; LHR, luteinizing hormone/choriogonadotropin receptor; PRL, prolactin receptor; ER $\alpha$, estrogen receptor $\alpha$; ER $\beta$, estrogen receptor $\beta$; ProgR, progesterone receptor; $\mathrm{AR}$, androgen receptor; $\mathrm{BMG}, \beta-2$ microglobulin.

as a negative control. In some experiments, ES-D3 cells were pretreated with inhibitors UO126 (1 $\mu \mathrm{M}$; Promega, Madison, WI, USA), MK2206 (1 $\mu \mathrm{M}$; Selleckchem, Houston, TX, USA), SB203580 $(10 \mu \mathrm{M}$; Tocris, Minneapolis, MN, USA) for $10 \mathrm{~min}$ and loaded to the upper chamber. For these experiments, inhibitors were also present in the lower chambers throughout the duration of the experiment. After $36 \mathrm{~h}$, the inserts were removed from the Transwell supports. The cells that had not migrated were scraped off with a cotton swab from the upper membrane, and the cells that had migrated to the lower side of the membrane were fixed and stained with HEMA 3 (following the manufacurer's protocol; Fisher Scientific, Pittsburgh, PA, USA) and counted on the lower side of the membrane using an inverted microscope.

Adhesion assay to fibronectin. Plates (96-wells) were coated with fibronectin $(10 \mu \mathrm{g} / \mathrm{ml})$ overnight at $4^{\circ} \mathrm{C}$ and blocked with $0.5 \% \mathrm{BSA}$ for $1 \mathrm{~h}$ before the experiment. The cells were made quiescent for $2 \mathrm{~h}$ with the appropriate medium (DMEM or MEM- $\alpha$ ) containing $0.5 \%$ BSA, followed by incubation with pituitary hormones for $10 \mathrm{~min}$. Subsequently, cell suspensions $\left(2 \times 10^{3}\right.$ cells $\left./ 100 \mu \mathrm{l}\right)$ were added directly to the fibronectin-coated wells and incubated for $5 \mathrm{~min}$ at $37^{\circ} \mathrm{C}$. Following incubation, non-adherent cells were removed, and fresh medium with BSA was added. The cells were incubated for an additional $10 \mathrm{~min}$, washed twice, and the number of adherent cells counted using an inverted microscope was performed as previously described (27).

Cell proliferation. Cells were seeded at an initial density of $1 \times 10^{4}$ cells $/ \mathrm{cm}^{2}$ (P19 and NTera2) or $0.5 \times 10^{4}$ cells $/ \mathrm{cm}^{2}$ (ES-D3). The medium was changed after $24 \mathrm{~h}$ to new medium supplemented with $0.5 \%$ BSA with or without hormones. For a positive control, new medium supplemented with $10 \%$ FBS was employed. At 24, 48 and $72 \mathrm{~h}$ after the medium was changed, the cells were trypsinized, stained with Trypan blue, and counted using a Neubauer chamber.

Statistical analysis. Statistical analysis was performed using the t-test (for data having a normal distribution) or the Mann-Whitney test (for data not having a normal distribution), with $\mathrm{P} \leq 0.05$ considered significant.

\section{Results}

Murine and human cell lines involved in early development express functional sex hormone (SexH) receptors. First, we employed RT-PCR to assess the expression of peptide- and steroid-based SexH receptors, and we determined that the analyzed cell lines expressed a majority of these receptors, including peptide-based SexH receptors (Fig. 1A). We additionally confirmed the presence of $\mathrm{FSH}$ and $\mathrm{LH}$ receptors on 
A

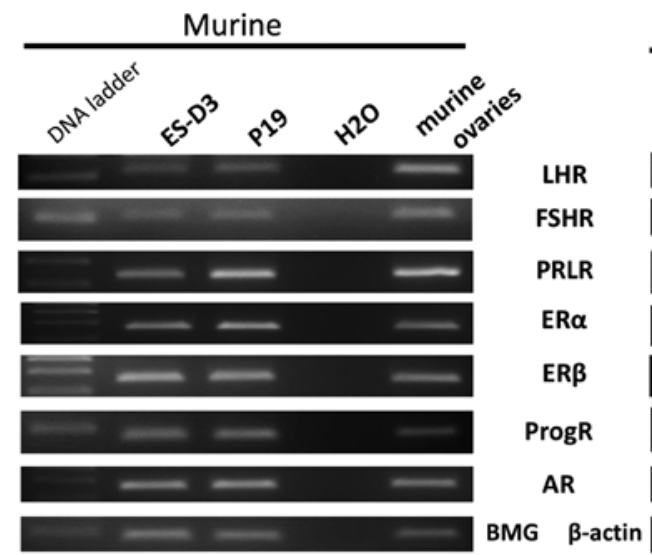

B

ES-D3
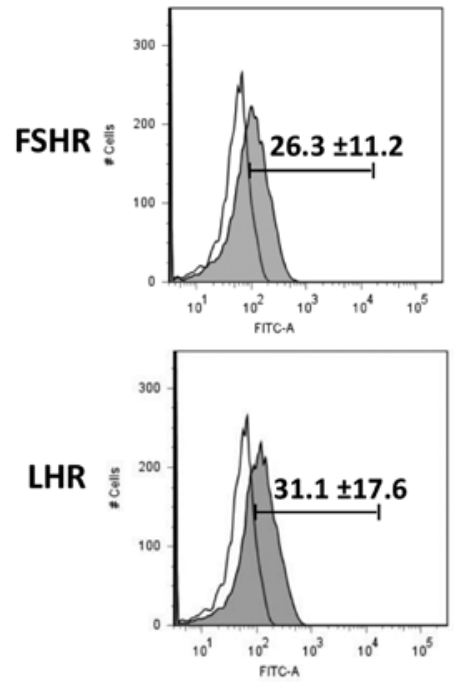

P19
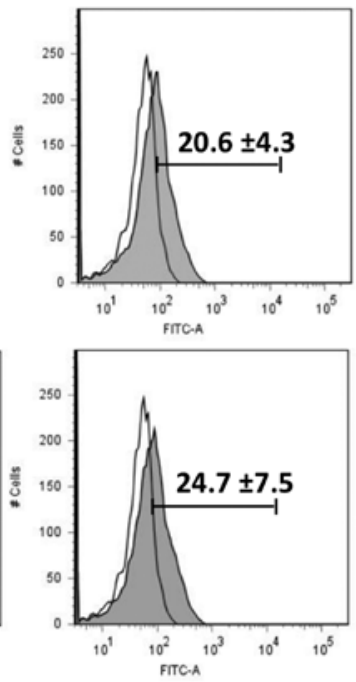

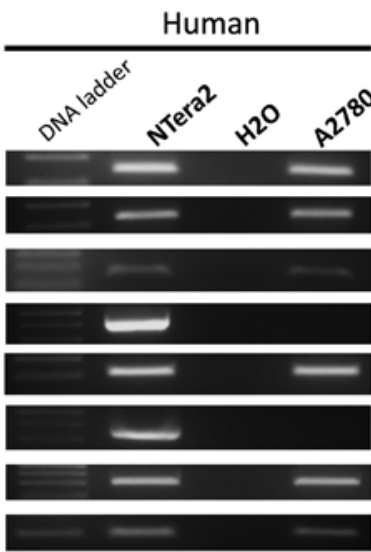

NTera2
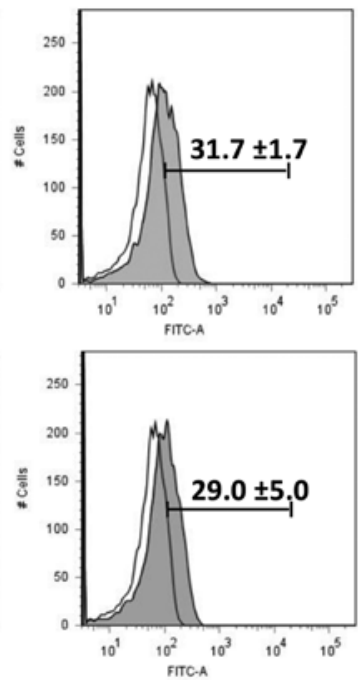

Figure 1. Murine and human early-developmental-stage cell lines express several sex hormone receptors. (A) RT-PCR results for expression of LHR, FSHR, PRLR, ER $\alpha, E R \beta$, ProgR, and AR in the murine stem cell line ES-D3, the teratocarcinoma cell line P19, and the human embryonal carcinoma cell line NTera2. cDNA from murine ovaries and from the human ovarian cancer cell line A2780 were used as controls. (B) Flow cytometric analysis of FSHR and LHR expression in the ES-D3, P19, and NTera2 cell lines. Representative results from two independent experiments are shown. LHR, luteinizing hormone receptor; FSHR, follicle stimulating hormone receptor; PRLR, prolactin receptor; ER $\alpha$, estrogen $\alpha$ receptor; ER $\beta$, estrogen $\beta$ receptor; ProgR, progesterone receptor; AR, androgen receptor.

the surface of the analyzed cell lines by FACS (Fig. 1B) and found that their expression was detectable on the surface of ES-D3, P19, and NTera2 cells.

To address whether FSH, LH, and PRL receptors were functional, we employed signal transduction experiments to examine whether stimulation with peptide-based SexHs activated signaling pathways involved in cell migration and adhesion. As shown in Fig. 2, all of the SexHs studied induced p42/44 MAPK, p38 MAPK and AKT phosphorylation; however, the pattern of activation depended on the cell type. While ES-D3 responded robustly to stimulation by $\mathrm{FSH}$, LH, and PRL by p42/44 MAPK and AKT stimulation, P19 and NTera 2 cells exhibited a strong response to FSH and a weaker response to LH. Robust activation of p38 MAPK was observed in all cell lines in response to $\mathrm{FSH}$, and in a less extent to $\mathrm{LH}$ and prolactin. The response of AKT to stimulation by pituitary SexHs was observed in ES-D3 and NTera2 cells after stimulation by FSH and LH and in P19 cells after exposure to FSH.

Peptide-based SexH receptors modulate the chemotactic responsiveness and adhesion of murine and human cell lines in the early developmental stage. To address whether SexHs modulated migration of the investigated murine and human cell lines, we employed the Transwell system, in which two chambers were separated with a porous membrane. The lower chamber was prefilled with warm medium supplemented with the studied SexHs, and the cells were seeded into the upper chamber. After $24 \mathrm{~h}$ the inserts were removed, and the cells that had migrated from the upper to the lower side of the membrane were stained and counted under a microscope. As shown in Fig. 3, all studied SexHs stimulated migration of ES-D3, P19, and NTera2 cells. Notably, all cell lines responded not only to supraphysiological concentrations of FSH and $\mathrm{LH}$ but also to lower concentrations detected in human plasma. By contrast, while ES-D3 cells responded to a steep gradient of PRL only (Fig. 3A), P19 and NTera2 cells were chemoattracted to a lower physiological dose of this hormone (Fig. 3B and C).

To address whether FSH-, LH-, and PRL-stimulated migration dependend on the activation of AKT, p42/44, and p38 MAPK signaling pathways, we assessed the migration of ES-D3 upon stimulation with LH,FSH and prolactin in the presence of the appropriate inhibitors. We determined that, while 


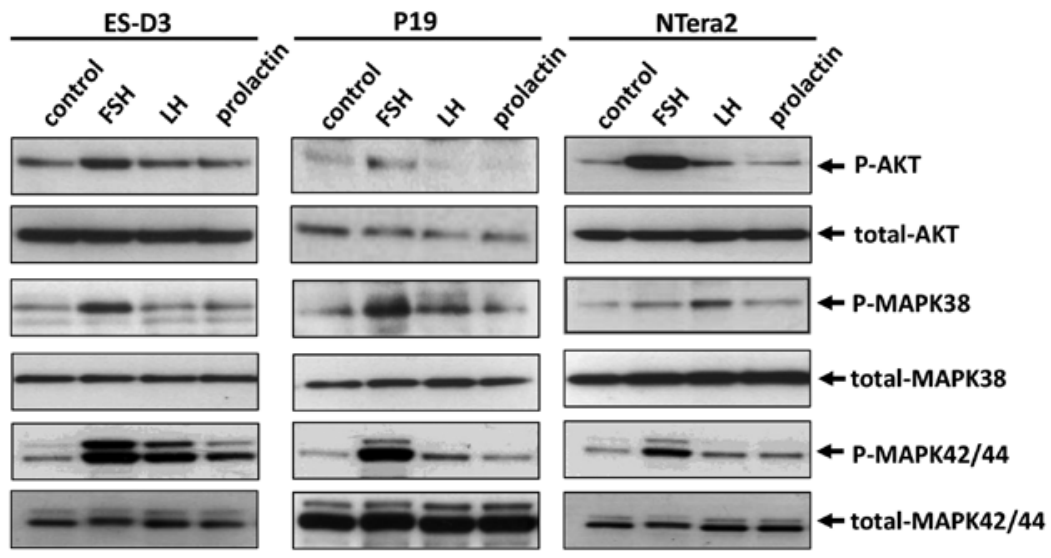

Figure 2. Pituitary sex hormone receptors are functional in murine and human cell lines in the early developmental stage. Western blot analysis of p42/44 MAPK, p38 MAPK and AKT phosphorylation (p-p42/44 MAPK, p-p38 MAPK and p-AKT) upon FSH, LH, and PRL stimulation of the ES-D3, P19, and NTera 2 cell lines. Representative results from two independent experiments are shown.
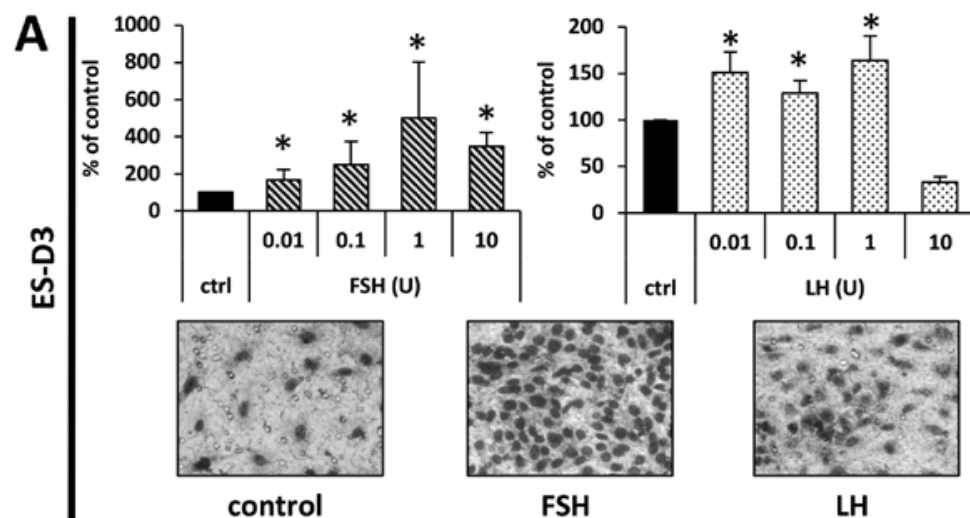

LH
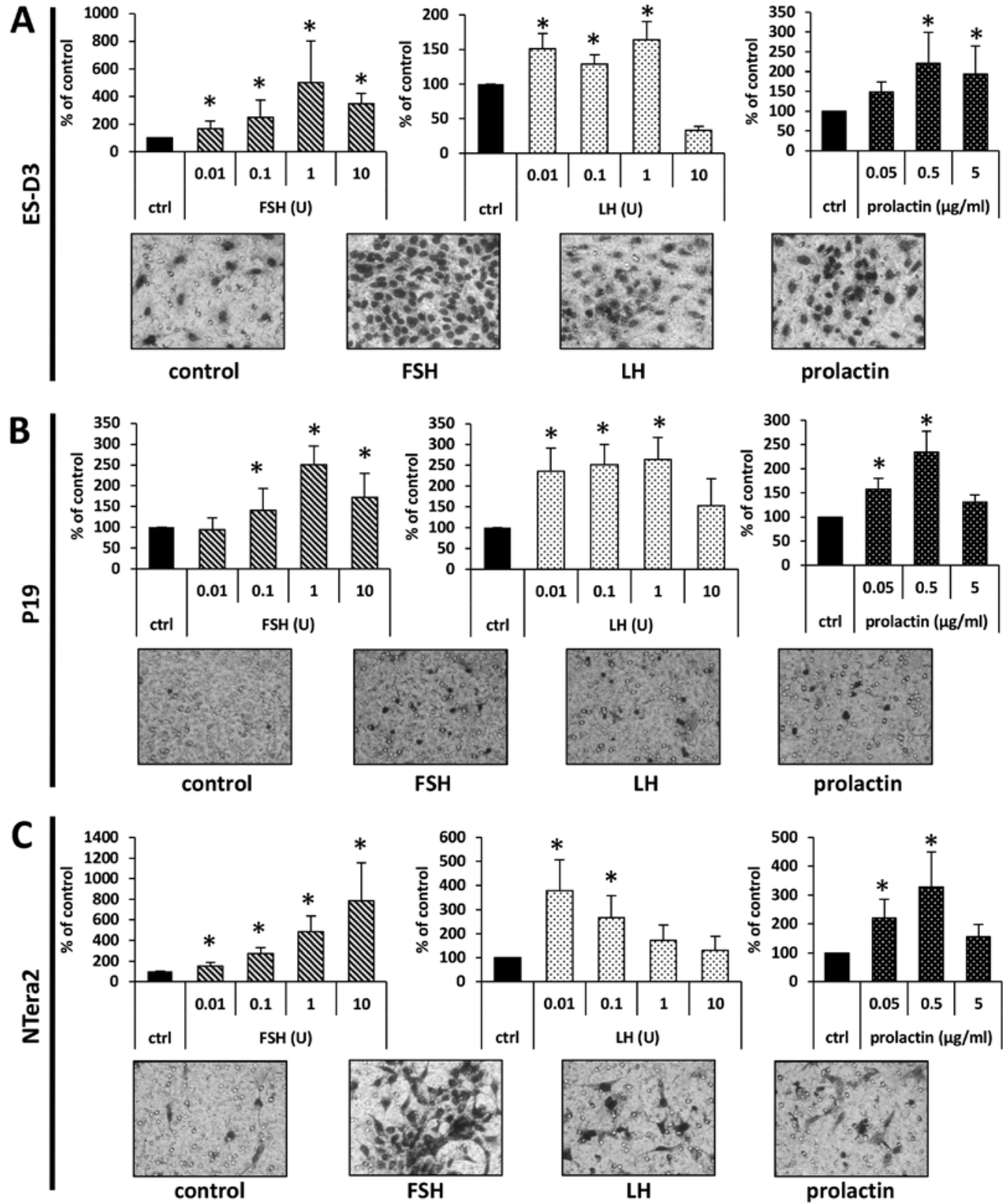

FSH

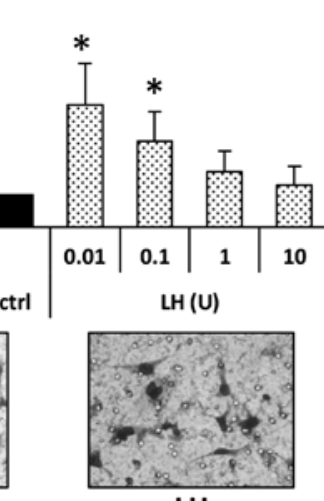

LH

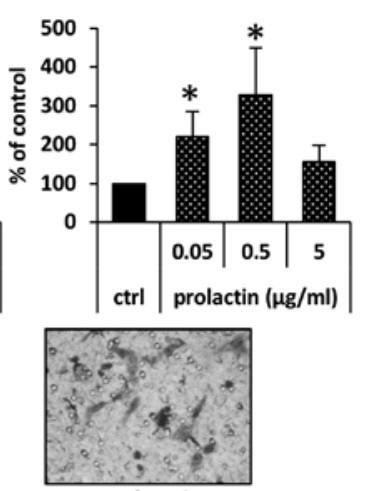

prolactin

Figure 3. Pituitary sex hormones stimulate the migration of murine and human cell lines in the early developmental stage. The effect of the pituitary hormone on the migration of (A) ES-D3, (B) P19, and (C) NTera2 cells. The migration of cells across Transwell membranes in response to pituitary hormones is presented graphically. Results from at least three experiments are shown, with " $\mathrm{P} \leq 0.5$. Representative images of stained membranes are shown beneath the graphs. 


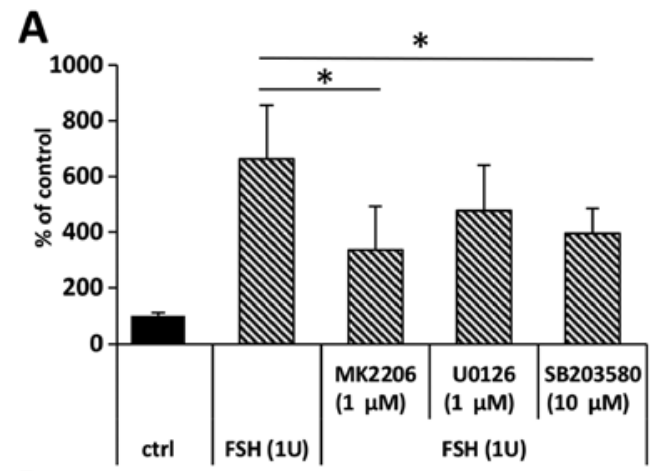

B
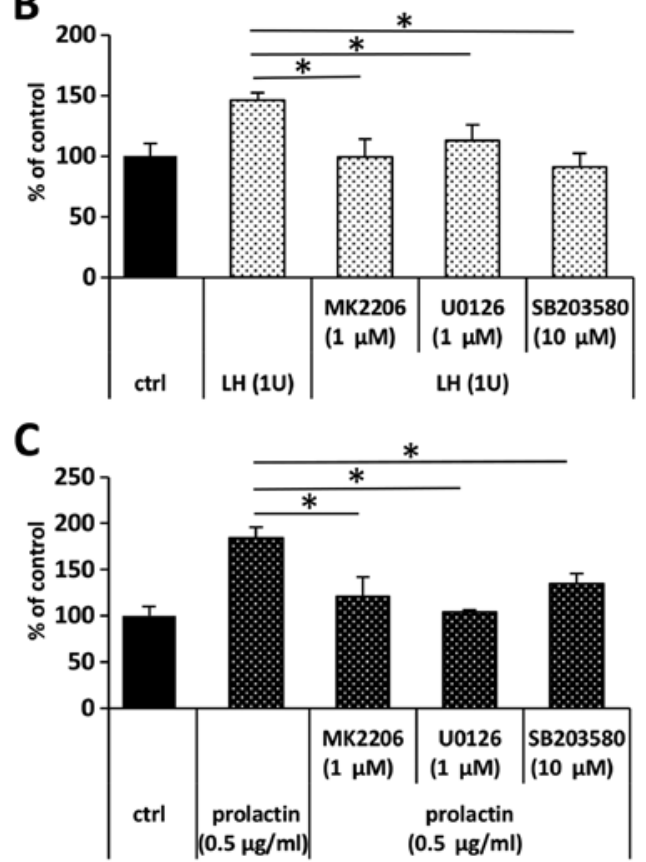

Figure 4. The pituitary sex hormone-stimulated migration of ES-D3 cells depends on the activation of AKT, p42/44 MAPK and p38. Pretreatment of ES-D3 cells with AKT (MK2206), p42/44 MAPK (U0136) and p38 MAPK (SB203580) inhibitors affected their migration upon stimulation with (A) FSH, (B) LH and (C) prolactin.

the response of ES-D3 cells to FSH stimulation was decreased only in the presence of AKT (MK2206) and p38 MAPK (SB203580) (Fig. 4A), their response to $\mathrm{LH}$ and prolactin was inhibited by MEK, AKT, and p38 MAPK inhibitors, UO126, MK2206, and SB203580, respectively (Fig. 4B and C).

We also analyzed whether pituitary SexHs increased adhesion of the cell lines investigated in our study and determined that stimulation of ES-D3, P19, and NTera2 cells with FSH, LH, and PRL induced adhesion of these cells to fibronectin (Fig. 5).

The effect of pituitary SexHs on the proliferation of murine and human cell lines early-developmental-stage. FSH, LH, and PRL are known to be potent mitogens for some types of cells. As shown in Figs. 6 and 7, we added SexHs at the indicated doses on day 0 and analyzed the number of cells 24, 48 and $72 \mathrm{~h}$ later. We observed that FSH slightly stimulated proliferation of ES-D3 (Fig. 6A) and NTera2 (Fig. 7) cells if added to medium containing $0.5 \%$ BSA. By contrast, no effect of LH or PRL was observed.
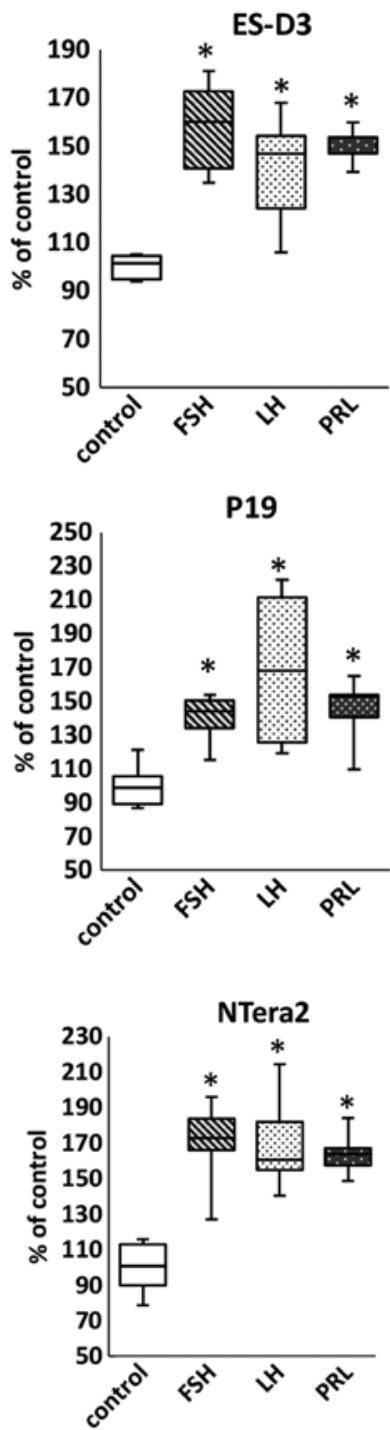

Figure 5. Pituitary sex hormones stimulate adhesion of murine and human cell lines in the early developmental stage. The effect of pituitary hormones on adhesion of ES-D3, P19, and NTera2 cells to fibronectin. Results from two experiments are shown with ${ }^{*} \mathrm{P} \leq 0.5$.

\section{Discussion}

The salient observation of this study is that established cell lines derived in early development, including the murine embryonic ES-D3, the murine teratocarcinoma P19, and the human embryonal carcinoma NTera2 cell lines, express functional SexH receptors. Thus, our results indicated that pituitary SexHs may affect the biology of murine and human stem cells during the earliest stages of embryogenesis. Moreover, placenta-derived PRL-like hormones (known as lactogens), which bind with high affinity to the PRL-receptor and thereby mimic the actions of PRL, may also be involved in this process (28).

Recently, it was demonstrated that pituitary SexHs were involved in metastatic lung cancer (9), certain sarcomas (10), and leukemia (11). In the present study we investigated whether FSH, LH, and PRL stimulated cells in the early developmental stage.

It is well known that pituitary SexHs affect development and regulate biological processes in gonadal, prostate, and 


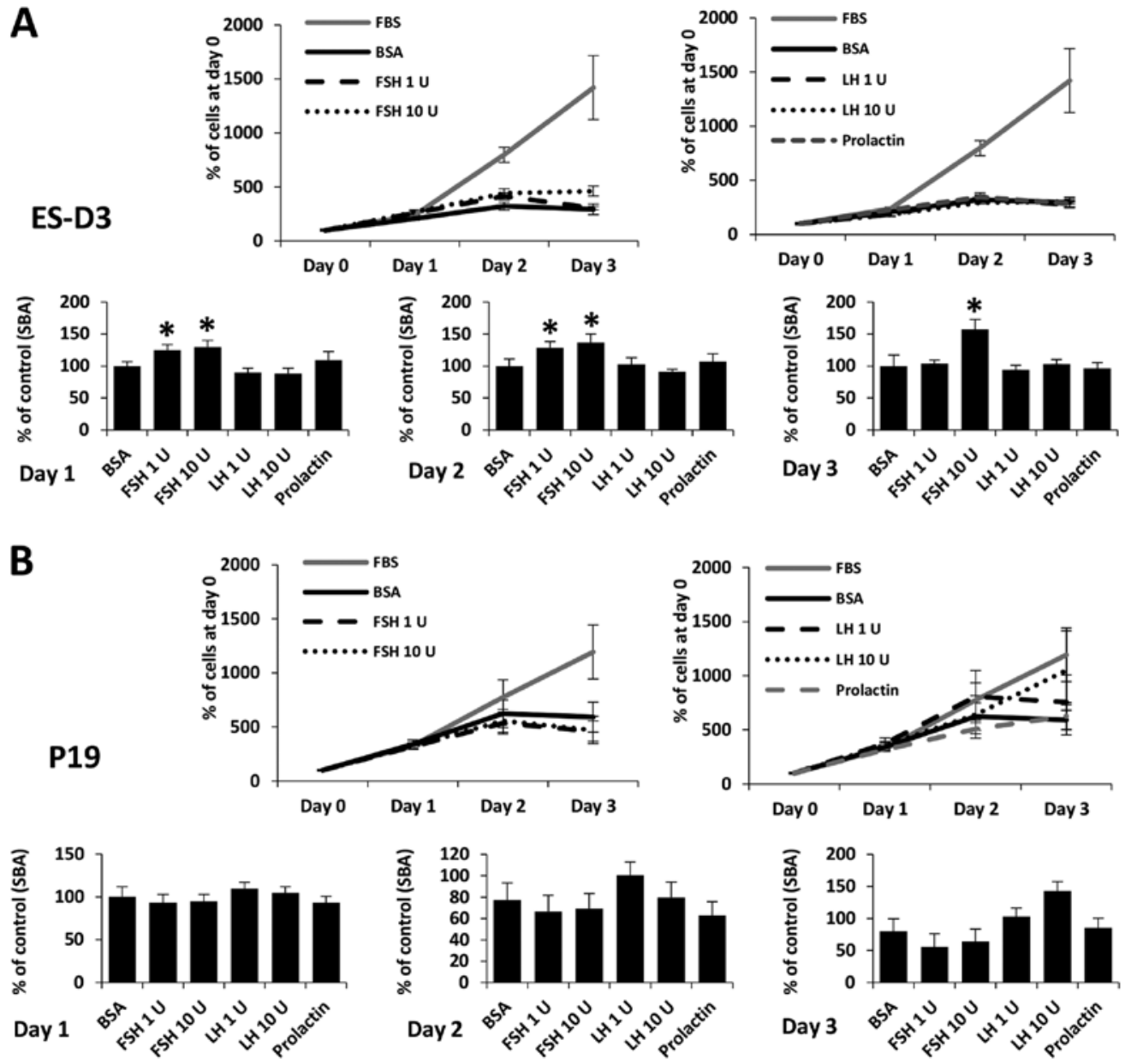

Figure 6. FSH stimulates proliferation of murine ES-D3, but not P19 cells. The effect of pituitary hormone on the proliferation of (A) ES-D3 and (B) P19 cells. In the upper line graphs, the values are the percentage of cells on day 0 . In the lower bar graphs, the values are normalized to the negative control, which represents $100 \%$ of cells on a particular day. For each cell line, the experiment was repeated twice in triplicate with similar results.
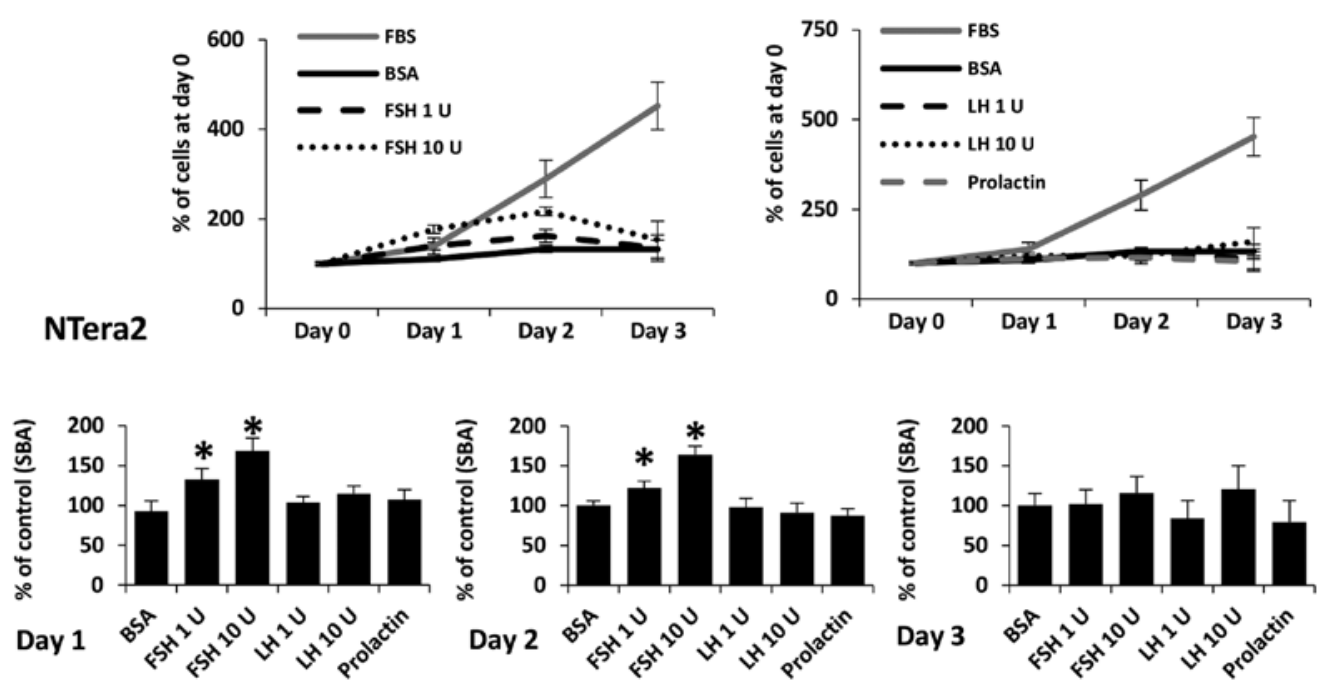

Figure 7. FSH stimulates proliferation of human Ntera2 cell line. The effect of pituitary sex hormones on the proliferation of NTera2 cells. In the upper line graphs, the values are the percentage of cells on day 0 . In the lower bar graphs, the values are normalized to the negative control, which represents $100 \%$ of cells on a particular day. For each cell line, the experiment was repeated twice in triplicate with similar results.

breast tissue (5-8). We recently demonstrated that pituitary SexHs were also involved in regulating normal hematopoiesis $(20,21)$, which supports their having direct pleiotropic effects on extra-gonadal tissues in the adult organism.
On the other hand, evidence has accumulated that pituitary SexHs are involved in gonadal, breast, and prostate malignancies (5-8). Recent evidence revealed as aforementioned that these hormones were also involved in the pathogenesis of lung 
cancer, pediatric sarcomas, and leukemia. In our current study we demonstrated for the first time that certain malignancies derived from cells involved in early development, such as murine P19 teratocarcinoma cells and human embryonal carcinoma NTera2 cells, were highly sensitive to pituitary SexH stimulation, even when employed at physiological concentrations in peripheral blood (29). Notably, the concentration of some SexHs, such as FSH, increase with advancing age as a result of age-dependent gonadal dysfunction $(30,31)$.

Our results are important for another reason. It has been proposed in the past that some cells from early embryonic development may continue to reside in adult tissues (18,19,32-34). This hypothesis was the basis for a theory proposed in the XIX century by Recamier (1829) (32), Remak (1854) (33), Virchow (1858) (18) and later elaborated by Durante (1874) (34) and Cohnheim (1875) (19) that some malignancies are derived from such embryonic remnants. This theory was known as the embryonic rest hypothesis for cancer development and was popular in older pathology textbooks $(18,19,32-34)$.

The presence of certain populations of primitive stem cells in adult tissues that are endowed with the ability to differentiate into all three germ layers has been proposed by several researchers. Examples of such cells described in the literature include i) multipotent adult progenitor cells (MAPCs) (35); ii) marrow-isolated adult multilineage-inducible (MIAMI) cells (36); iii) multipotent adult stem cells (MASCs) (37); iv) elutriation-derived (Fr25/Lin') stem cells (ELH SCs) (38); v) spore-like stem cells (39); vi) pluripotent $\mathrm{Sca}-1^{+} \mathrm{CD} 45^{-} \mathrm{c}-\mathrm{kit}$ cells (40); and vii) multilineage-differentiating stress-enduring stem cells (Muse SCs) (41). An interesting population of stem cells endowed with pan-germ-layer differentiation potential has been identified by our team and confirmed subsequently by several independent researchers as very small embryonic-like stem cells (VSELs) $(15,20-25,42-45)$. The similarity of all the stem cells listed above with respect to the expression of certain genes involved in early development suggests that they are related to each other, that they represent similar and overlapping populations of primitive SCs that reside in adult tissues, and that they are endowed with broader pan-germ-layer differentiation potential (46). These stem cell types were identified by employing different direct or indirect isolation protocols and identification techniques, and based on this they were given different names. We propose that, due to their primitive embryonic morphology and gene expression for embryonic and primordial germline markers, VSELs are at the top of the hierarchy of these cells, which is consistent with an old concept that germline stem cells are not only developmental in origin but also remain as a 'skeleton' of the stem cell compartment in adult tissues (46).

We demonstrated in the past that VSELs express several receptors for SexHs, and our results reported in this study support the finding that the most primitive stem cells originating during development are responsive to SexHs (20-25). Since the pituitary gland develops later in embryogenesis, several of these hormones are derived from maternal blood, and in fact the potential effects of pituitary and placental SexHs on the developing embryo are not very well addressed in literature.

Cell migration and adhesion are regulated by different factors, such as chemokines, growth factors, cytokines, bioactive lipids, and extracellular nucleotides (27,47-49). However our recent and already published results indicate that pituitary SexHs also play an important role, which has been observed in both normal and malignant cells (9-11,20-23). While pituitary SexHs were found to increase the proliferation of several tumors, we observed only a very weak effect of FSH on proliferation of ES-D3 and NTera-2 cells. The role of pituitary SexHs, in particular, in the pathogenesis of cancer requires further study, since, as aforementioned, the concentration of FSH in peripheral blood increases with age due to gonadal dysfunction $(30,31)$.

In conclusion, we found that pituitary SexHs stimulated migration and adhesion of established immortalized cell lines derived from the inner cell mass of the blastocyst (ES-D3) as well as from early germline tumors (P19, NTera2). Therefore, pituitary SexHs derived from maternal blood may affect the early stages of embryonic development. Moreover, lactogens, which can bind with high affinity to the PRL-receptor and thereby mimic the actions PRL, may also be involved in this process (28). This possibility, however, requires further study.

Our observations also shed new light on the potential role of these hormones in early embryonic development and cancerogenesis, particularly in light of the embryonic rest hypothesis proposed by Virchow and Connheim $(18,19)$. However, we are aware that this concept also warrants more experimental investigation.

\section{Acknowledgements}

This study was supported by NIH grants 2R01 DK074720 and R01HL112788, the Stella and Henry Endowment, and NCN grant: OPUS 2016/21/B/NZ4/00201 by the National Science Center in Poland to MK.

\section{References}

1. Costa MA: The endocrine function of human placenta: An overview. Reprod Biomed Online 32: 14-43, 2016.

2. Pepe GJ and Albrecht ED: Actions of placental and fetal adrenal steroid hormones in primate pregnancy. Endocr Rev 16: 608-648, 1995.

3. Whitaker-Azmitia PM, Lobel M and Moyer A: Low maternal progesterone may contribute to both obstetrical complications and autism. Med Hypotheses 82: 313-318, 2014.

4. Gürbüz B, Yalti S, Ozden S and Ficicioglu C: High basal estradiol level and FSH/LH ratio in unexplained recurrent pregnancy loss. Arch Gynecol Obstet 270: 37-39, 2004.

5. van Kruchten M, van der Marel P, de Munck L, Hollema H, Arts H, Timmer-Bosscha H, de Vries E, Hospers G and Reyners A: Hormone receptors as a marker of poor survival in epithelial ovarian cancer. Gynecol Oncol 138: 634-639, 2015.

6. Lønning PE: Poor-prognosis estrogen receptor-positive disease: Present and future clinical solutions. Ther Adv Med Oncol 4: 127-137, 2012.

7. García-Cruz E, Piqueras M, Huguet J, Peri L, Izquierdo L, Musquera M, Franco A, Alvarez-Vijande R, Ribal MJ and Alcaraz A: Low testosterone levels are related to poor prognosis factors in men with prostate cancer prior to treatment. BJU Int 110: E541-E546, 2012.

8. Ma CX, Bose R and Ellis MJ: Prognostic and predictive biomarkers of endocrine responsiveness for estrogen receptor positive breast cancer. Adv Exp Med Biol 882: 125-154, 2016.

9. Abdelbaset-Ismail A, Pedziwiatr D, Schneider G, Niklinski J, Charkiewicz R, Moniuszko M, Kucia M and Ratajczak MZ: Pituitary sex hormones enhance the pro metastatic potential of human lung cancer cells by downregulating the intracellular expression of heme oxygenase 1. Int J Oncol 50: 317-328, 2017. 
10. Poniewierska-Baran A, Schneider G, Sun W, Abdelbaset-Ismail A, Barr FG and Ratajczak MZ: Human rhabdomyosarcoma cells express functional pituitary and gonadal sex hormone receptors: Therapeutic implications. Int J Oncol 48: 1815-1824, 2016.

11. Abdelbaset-Ismail A, Borkowska S, Janowska-Wieczorek A, Tonn T, Rodriguez C, Moniuszko M, Bolkun L, Koloczko J, Eljaszewicz A, Ratajczak J, et al: Novel evidence that pituitary gonadotropins directly stimulate human leukemic cells-studies of myeloid cell lines and primary patient AML and CML cells. Oncotarget 7: 3033-3046, 2016.

12. Donovan PJ and Gearhart J: The end of the beginning for pluripotent stem cells. Nature 414: 92-97, 2001.

13. Otte J, Wruck W and Adjaye J: New insights into human primordial germ cells and early embryonic development from single-cell analysis. FEBS Lett 591: 2226-2240, 2017.

14. Aflatoonian B and Moore H: Germ cells from mouse and human embryonic stem cells. Reproduction 132: 699-707, 2006.

15. Kucia M, Halasa M, Wysoczynski M, Baskiewicz-Masiuk M, Moldenhawer S, Zuba-Surma E, Czajka R, Wojakowski W, Machalinski B and Ratajczak MZ: Morphological and molecular characterization of novel population of CXCR $4^{+}$SSEA- $4^{+}$Oct- $4^{+}$ very small embryonic-like cells purified from human cord blood: Preliminary report. Leukemia 21: 297-303, 2007.

16. Ratajczak MZ, Shin DM, Liu R, Marlicz W, Tarnowski M, Ratajczak J and Kucia M: Epiblast/germ line hypothesis of cancer development revisited: Lesson from the presence of Oct- $4^{+}$cells in adult tissues. Stem Cell Rev 6: 307-316, 2010.

17. Ratajczak MZ, Schneider G, Sellers ZP, Kucia M and Kakar SS: The embryonic rest hypothesis of cancer development - an old XIX century theory revisited. J Cancer Stem Cell Res 2: e1001, 2014.

18. Virchow R: Editorial Archive fuer pathologische. Anatomie und Physiologie fuer klinische Medizin 8: 23-54, 1855 (In German).

19. Conheim J: Congenitales, quergestreiftes muskelsarkon der nireren. Virchows Arch 65: 64-69, 1875 (In German).

20. Mierzejewska K, Borkowska S, Suszynska E, Suszynska M, Poniewierska-Baran A, Maj M, Pedziwiatr D, Adamiak M, Abdel-Latif A, Kakar SS, et al: Hematopoietic stem/progenitor cells express several functional sex hormone receptors-novel evidence for a potential developmental link between hematopoiesis and primordial germ cells. Stem Cells Dev 24: 927-937, 2015.

21. Abdelbaset-Ismail A, Suszynska M, Borkowska S, Adamiak M, Ratajczak J, Kucia M and Ratajczak MZ: Human haematopoietic stem/progenitor cells express several functional sex hormone receptors. J Cell Mol Med 20: 134-146, 2016.

22. Patel H and Bhartiya D: Testicular stem cells express follicle-stimulating hormone receptors and are directly modulated by FSH. Reprod Sci 23: 1493-1508, 2016

23. Patel H, Bhartiya D, Parte S, Gunjal P, Yedurkar S and Bhatt M Follicle stimulating hormone modulates ovarian stem cells through alternately spliced receptor variant FSH-R3. J Ovarian Res 6: 52, 2013.

24. Shaikh A, Anand S, Kapoor S, Ganguly R and Bhartiya D: Mouse bone marrow VSELs exhibit differentiation into three embryonic germ lineages and germ \& hematopoietic cells in culture. Stem Cell Rev 13: 202-216, 2017.

25. Ratajczak MZ, Bartke A and Darzynkiewicz Z: Prolonged growth hormone/insulin/insulin-like growth factor nutrient response signaling pathway as a silent killer of stem cells and a culprit in aging. Stem Cell Rev 13: 443-453, 2017.

26. Sellers ZP, Schneider G, Bujko K, Suszynska M and Pedziwiatr D: Do cancer cell lines have fixed or fluctuating stem cell phenotypes? - studies with the NTera 2 cell line. Stem Cell Rev 13: 603-610, 2017.

27. Schneider G, Glaser T, Lameu C, Abdelbaset-Ismail A, Sellers ZP, Moniuszko M, Ulrich H and Ratajczak MZ: Extracellular nucleotides as novel, underappreciated pro-metastatic factors that stimulate purinergic signaling in human lung cancer cells. Mol Cancer 14: 201, 2015.

28. Gertler A, Bignon C, Staten NR, Sakal E, Tchelet A, Krivi GG and Djiane J; Proceedings of the Society for Experimental Biology and Medicine: Interaction of lactogenic hormones with the soluble extracellular domain of prolactin receptors. Proc Soc Exp Biol Med 206: 273-279, 1994.

29. Fischbach F and Dunning MB: A Manual of Laboratory and Diagnostic Tests. 9th edition. Wolters Kluwer Health/Lippincott Williams \& Wilkins, Philadelphia, 2014.

30. Araujo $\mathrm{AB}$ and Wittert GA: Endocrinology of the aging male Best Pract Res Clin Endocrinol Metab 25: 303-319, 2011.
31. Limpaphayom K, Taechakraichana $\mathrm{N}$ and Kittinunvorakoon $\mathrm{C}$ : Serum estradiol and gonadotropins level in postmenopausal women with or without hormone replacement. J Med Assoc Thai 80: 147-152, 1997.

32. Androutsos G, Karamanou M, Stamboulis E, Tsoucalas G, Kousoulis AA and Mandelenaki D: Joseph-Claude-Anthelme Récamier (1774-1852): Forerunner in surgical oncology. J BUON 16: 572-576, 2011

33. Remak R: Ein beitrag zur entwickelungsgeschichte der krebshaften geschwulste Deut Klin 6: 70-174, 1854 (In German).

34. Durante F: Arch. Memori ed Osservazioni di Chirugia Practica 11: 217-226, 1874 (In Italian).

35. Jiang Y, Jahagirdar BN, Reinhardt RL, Schwartz RE, Keene CD, Ortiz-Gonzalez XR, Reyes M, Lenvik T, Lund T, Blackstad M, et al: Pluripotency of mesenchymal stem cells derived from adult marrow. Nature 418: 41-49, 2002.

36. D'Ippolito G, Diabira S, Howard GA, Menei P, Roos BA and Schiller PC: Marrow-isolated adult multilineage inducible (MIAMI) cells, a unique population of postnatal young and old human cells with extensive expansion and differentiation potential. J Cell Sci 117: 2971-2981, 2004.

37. Beltrami AP, Cesselli D, Bergamin N, Marcon P, Rigo S, Puppato E, D'Aurizio F, Verardo R, Piazza S, Pignatelli A, et al: Multipotent cells can be generated in vitro from several adult human organs (heart, liver, and bone marrow). Blood 110: 3438-3446, 2007.

38. Goldenberg-Cohen N, Avraham-Lubin BC, Sadikov T, Goldstein RS and Askenasy N: Primitive stem cells derived from bone marrow express glial and neuronal markers and support revascularization in injured retina exposed to ischemic and mechanical damage. Stem Cells Dev 21: 1488-1500, 2012.

39. Vacanti MP, Roy A, Cortiella J, Bonassar L and Vacanti CA: Identification and initial characterization of spore-like cells in adult mammals. J Cell Biochem 80: 455-460, 2001.

40. Howell JC, Lee WH, Morrison P, Zhong J, Yoder MC and Srour EF: Pluripotent stem cells identified in multiple murine tissues. Ann NY Acad Sci 996: 158-173, 2003.

41. Wakao S, Kitada M, Kuroda Y, Shigemoto T, Matsuse D, Akashi H, Tanimura Y, Tsuchiyama K, Kikuchi T, Goda M, et al: Multilineage-differentiating stress-enduring (Muse) cells are a primary source of induced pluripotent stem cells in human fibroblasts. Proc Natl Acad Sci USA 108: 9875-9880, 2011.

42. Guerin CL, Rossi E, Saubamea B, Cras A, Mignon V, Silvestre JS and Smadja DM: Human very small embryonic-like cells support vascular maturation and therapeutic revascularization induced by endothelial progenitor cells. Stem Cell Rev 13: 552-560, 2017.

43. Golipoor Z, Mehraein F, Zafari F, Alizadeh A, Ababzadeh S and Baazm M: Migration of bone marrow-derived very small embryonic-like stem cells toward an injured spinal cord. Cell J 17: 639-647, 2016.

44. Bhartiya D, Shaikh A, Anand S, Patel H, Kapoor S, Sriraman K, Parte S and Unni S: Endogenous, very small embryonic-like stem cells: Critical review, therapeutic potential and a look ahead. Hum Reprod Update 23: 41-76, 2016

45. Kassmer SH, Jin H, Zhang PX, Bruscia EM, Heydari K, Lee JH, Kim CF, Kassmer SH and Krause DS: Very small embryoniclike stem cells from the murine bone marrow differentiate into epithelial cells of the lung. Stem Cells 31: 2759-2766, 2013

46. Ratajczak MZ, Ratajczak J, Suszynska M, Miller DM, Kucia M and Shin DM: A novel view of the adult stem cell compartment from the perspective of a quiescent population of very small embryonic-like stem cells. Circ Res 120: 166-178, 2017.

47. Majka M, Drukala J, Lesko E, Wysoczynski M, Jenson AB and Ratajczak MZ: SDF-1 alone and in co-operation with HGF regulates biology of human cervical carcinoma cells. Folia Histochem Cytobiol 44: 155-164, 2006.

48. Schneider G, Sellers ZP, Bujko K, Kakar SS, Kucia M and Ratajczak MZ: Novel pleiotropic effects of bioactive phospholipids in human lung cancer metastasis. Oncotarget 8: 58247-58263, 2017

49. Schneider G, Bryndza E, Poniewierska-Baran A, Serwin K, Suszynska M, Sellers ZP, Merchant ML, Kaliappan A, Ratajczak J, Kucia M, et al: Evidence that vitronectin is a potent migration-enhancing factor for cancer cells chaperoned by fibrinogen: A novel view of the metastasis of cancer cells to low-fibrinogen lymphatics and body cavities. Oncotarget 7: 69829-69843, 2016. 